\title{
Magnesium affects spinach carotenoid bioaccessibility in vitro depending on intestinal bile and pancreatic enzyme concentrations
}

\author{
Joana Corte-Real $^{\mathrm{a}, \mathrm{b}, \mathrm{c}}$, Charles Desmarchelier ${ }^{\mathrm{d}}$, Patrick Borel ${ }^{\mathrm{d}}$, Elke Richling ${ }^{\mathrm{b}}$, Lucien Hoffmann ${ }^{\mathrm{b}}$, Torsten Bohn ${ }^{\mathrm{a}, *}$

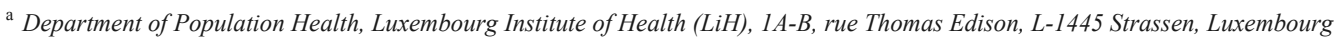 \\ ${ }^{\mathrm{b}}$ Environmental Research and Innovation (ERIN) Department, Luxembourg Institute of Science and Technology (LIST), 41 rue du Brill, L-4422 Belvaux, Luxembourg \\ ${ }^{\mathrm{c}}$ Food Chemistry and Toxicology, Department of Chemistry, University of Kaiserslautern, Erwin-Schroedinger-Strasse 52, D-67663 Kaiserslautern, Germany \\ d NORT, Aix-Marseille Université, INRA, INSERM, 13005 Marseille, France
}

\section{A R T I C L E IN F O}

Article history:

Received 11 May 2017

Received in revised form 27 June 2017

Accepted 28 June 2017

Available online $\mathrm{xxx}$

\section{Keywords:}

Lutein

Carotenes

Divalent minerals

Calcium

Bioavailability

Digestion

Lipids

Micelle formation

\section{A B S T R A C T}

Magnesium may reduce carotenoid bioavailability by forming insoluble complexes with bile salts/fatty acids, inhibiting micelle formation. Here, we investigated whether altering bile/pancreatin concentration influenced potential negative effects of magnesium on carotenoid bioaccessibility. Spinach $(4 \mathrm{~g})$ was digested in vitro with added magnesium $(0,200,400 \mathrm{mg} / \mathrm{L})$ and canola oil/coffee creamer, at varying bile extract $(1 \mathrm{or} 8 \mathrm{mM})$ and pancreatin (100 or $990 \mathrm{mg} / \mathrm{L})$ concentrations. Bioaccessibility was determined for $\beta$-carotene, lutein, and total carotenoids via HPLC. Additionally, lipolysis, particle size, and zeta potential of the micellar fractions were investigated. Increasing magnesium concentrations negatively affected carotenoid bioaccessibility $(\mathrm{p}<0.001)$, lipolysis, particle size and zeta potential. The impact of magnesium on carotenoid bioaccessibility was modulated mainly by bile concentration, with samples digested with $1 \mathrm{mM}$ of bile being more susceptible to inhibitory effects of magnesium than those digested with $8 \mathrm{mM}(\mathrm{p}<0.001)$. Thus, magnesium was found to potentially interfere with carotenoid bioaccessibility at various physiologically plausible conditions.

(C) 2017

\section{Introduction}

Carotenoids are lipophilic C30- and C40-based secondary plant compounds, recognized mainly for their anti-oxidant potential. Several carotenoids, such as $\beta$-carotene and $\beta$-cryptoxanthin, can also act as vitamin A precursors, and lutein and zeaxanthin have been suggested to protect against age-related macular degeneration (Lima, Rosen, \& Farah, 2016; Scripsema, Hu, \& Rosen, 2015). Though their mechanism of action have not been completely elucidated, direct anti-oxidant effects (Krinsky \& Yeum, 2003), and modulation of the expression of genes involved in inflammatory and anti-oxidant pathways (Kaulmann \& Bohn, 2014), likely play a role.

Carotenoid absorption efficiency is rather low and variable. It depends on both dietary (Desmarchelier \& Borel, 2017) and host-related factors (Bohn et al., 2017). The food matrix is considered to be a key factor, as, in order to be absorbed, carotenoids first need to be extracted from their food matrix and incorporated into mixed micelles. This process of transferring carotenoids from the food matrix into lipid globules already starts in the stomach. By the time carotenoids reach the small intestine, bile acids and pancreatic lipase are released into the duodenum, stimulated by dietary fat. While pancreatic enzymes break down lipids, bile, acting as a surfactant, facili-

\footnotetext{
* Corresponding author.

Email address: torsten.bohn@gmx.ch (T. Bohn)
}

tates the formation of smaller sized mixed bile-lipid micelles that enclose carotenoids (Britton, Liaaen-Jensen, \& Pfander, 2009).

Recently, it has been hypothesized (Biehler, Hoffmann, Krause, \& Bohn, 2011) that dietary divalent cations, such as calcium and magnesium could negatively affect carotenoid absorption, by preventing the formation of mixed-micelles as a result of fatty acid (Atteh \& Leeson, 1985; Boyd, Crum, \& Lyman, 1932) and bile salt precipitation (Gu, Hofmann, Ton-Nu, Schteingart, \& Mysels, 1992; Hofmann $\&$ Mysels, 1992). This has been shown in vitro for a variety of divalent cations and trace elements, following simulated digestion experiments with isolated carotenoids (Corte-Real et al., 2016) and carotenoids released from regular food matrices, such as spinach or carrot juice (Corte-Real, Bertucci et al., 2017). The concentrations required to observe these negative effects were equivalent to approximately half the recommended dietary allowance (RDA) for calcium and magnesium. However, recent human trials investigating the effect of calcium have found contradictory results. While in a study employing tomato paste, $500 \mathrm{mg}$ of calcium decreased post-prandial plasma lycopene concentration (Borel et al., 2016), another trial employing spinach and calcium doses of 500 and $1000 \mathrm{mg}$ did not find any significant changes in carotenoid concentrations in plasma triacylglycerol-rich lipoprotein (TRL) fractions (Corte-Real, Guignard et al., 2017).

While thus the findings remain controversial, even less information is available on the potential influence of dietary magnesium, the 
second most abundant dietary cation after calcium (RDA: $1000 \mathrm{mg}$ / d), with an RDA of $400 \mathrm{mg} / \mathrm{d}$ (Institute of Medicine, 2005). In vivo, the interaction between magnesium and other divalent cations and carotenoids is likely to be influenced by varying concentrations of bile and pancreatic enzymes, reflecting a more adaptive system compared to the in vitro static situations employed previously (Alminger et al., 2014; Biehler \& Bohn, 2010). Magnesium also has the ability to bind triglycerides and form soaps of different solubility, depending on the degree of fatty acid chain saturation. Magnesium soaps formed from saturated fatty acids showed lower solubility than those from unsaturated fatty acids (Bohn, 2008), which could lead to precipitation and fat excretion (Tadayyon \& Lutwak, 1969).

In the present trial, we investigated whether altering factors required for the micellarization of carotenoids (i.e. type and source of lipids, and bile and pancreatic enzyme concentrations) would influence the effect of magnesium on the bioaccessibility of carotenoids, as determined by fractional carotenoid bioaccessibility, following in vitro gastro-intestinal digestion. Frozen spinach leaves were chosen as a model matrix due to their high carotenoid content $(>5 \mathrm{mg} / 100 \mathrm{~g})$, the presence of both xanthophylls (lutein, neoxanthin and violaxanthin) and carotenes ( $\beta$ - and $\alpha$-carotene), and their previous use as a model vegetable (Biehler, Hoffmann et al., 2011; Castenmiller, West, Linssen, van het Hof, \& Voragen, 1999; Corte-Real, Bertucci et al., 2017; Rock et al., 1998). As the interactions are expected to affect the extent of lipolysis and the micelle size and stability of the colloidal system, these parameters were also assessed.

\section{Materials and methods}

\subsection{Chemicals and standards}

Pepsin (porcine, $\geq 250$ units/mg solid, measured as trichloroacetic acid (TCA)-soluble products using hemoglobin as substrate), pancreatin (porcine, 4X USP specifications), and porcine bile extract were purchased from Sigma-Aldrich (Bornem, Belgium). Methanol $(\mathrm{MeOH})$, hexane and hydrochloric acid were from VWR (Leuven, Belgium); acetone, sodium carbonate and sodium chloride from Merck (Darmstadt, Germany); methyl tert-butyl ether (MTBE) was purchased from Sigma Aldrich; acetonitrile (ACN) and dichloromethane (DCM) were obtained from Carl Roth (Karlsruhe, Germany). Beta-carotene and $\beta$-apo- 8 -carotenal standards were from Sigma Aldrich (purity $>95 \%$ ), while neoxanthin and lutein were from CaroteNature GmbH (Ostermundigen, Switzerland). Calcium chloride anhydrous was purchased from VWR and magnesium chloride anhydrous from Sigma Aldrich. Unless otherwise specified, all products were of analytical grade or higher. $18 \mathrm{M} \Omega$ water was prepared with a purification system from Millipore (Brussels, Belgium) and used throughout the study. As dietary lipid sources for the solubilisation of pure carotenoids, canola oil (purchased at a local supermarket CACTUS S.A., Windhof, Luxembourg) and INEX coffee creamer (10\% fat, Delhaize supermarket Esch-sur-Alzette, Luxembourg) were used. Both were previously employed to aid in the micellarization of carotenoids (Biehler, Kaulmann, Hoffmann, Krause, \& Bohn, 2011; Corte-Real, Richling, Hoffmann, \& Bohn, 2014; Corte-Real et al., 2016). The carotenoid containing food matrix, spinach (Spinachia oleracea), was purchased in frozen raw form (Cora supermarket, Foetz, Luxembourg).

\subsection{Simulation of gastro-intestinal digestion and factors investigated}

The in vitro digestion protocol was described earlier (Corte-Real et al., 2014). The model was used to test the effect of magnesium (at
0,200 and $400 \mathrm{mg} / \mathrm{L}$ ) on spinach carotenoid bioaccessibility, as a function of bile extract ( 1 and $8 \mathrm{mM})$ and pancreatin (100 and 990 $\mathrm{mg} / \mathrm{L}$ ) concentrations, expressed as concentrations after small intestinal digestion. Concentrations of enzymes and bile were chosen to represent plausible physiological ranges (Alminger et al., 2014). Concentrations of minerals were those representing earlier observed inhibitory concentrations (Corte-Real et al., 2016) and the upper tolerable limit (UL) (Institute of Medicine, 2005). In addition, the influence of lipid source from either canola oil or coffee creamer ( $10 \%$ fat) was studied. These were chosen to represent lipids easily soluble (coffee creamer) with the bulk of the food and a typical oil dressing, and also, as an earlier investigation suggested, different behavior on carotenoid bioaccessibility (Corte-Real et al., 2014).

Spinach aliquots were left to unfreeze, the excess water was drained, and the leaves were patted dry. Spinach was then further homogenized by maceration in a mortar, using liquid nitrogen. The homogenized spinach was weighed and aliquoted into polypropylene sample containers, flushed with argon and stored at $-80^{\circ} \mathrm{C}$. Test meals for digestion contained $4 \mathrm{~g}$ (wet weight) spinach plus either $0.3 \mathrm{~mL}$ of canola oil or $2 \mathrm{~mL}$ of coffee creamer (10\% fat) (approximately 250 $\mathrm{mg}$ of fat, i.e. $6 \%$ of the test meal). A solution of magnesium chloride was added to test meals, to achieve targeted concentrations, and digestion proceeded with a gastric phase carried out at $\mathrm{pH} 3$, for $1 \mathrm{~h}$ at $37^{\circ} \mathrm{C}$, followed by an intestinal phase at $\mathrm{pH} 7$, for $2 \mathrm{~h}$ at $37^{\circ} \mathrm{C}$. The final volume of digesta was $50 \mathrm{~mL}$ in physiological saline. These were then centrifuged briefly $(5 \mathrm{~min}, 2000 \mathrm{~g})$ and either processed further directly (bioaccessibility) or snap frozen at $-80{ }^{\circ} \mathrm{C}$ for further investigation (micelle size, zeta potential).

\subsection{Separation of bioaccessible fraction and bioaccessibility calculation}

Aliquots of digesta $(12 \mathrm{~mL})$ were transferred to $15 \mathrm{~mL}$ falcon tubes and centrifuged at $4800 \mathrm{~g}$ for $1 \mathrm{~h}$ at $4{ }^{\circ} \mathrm{C}$. Following centrifugation, 4 $\mathrm{mL}$ were collected from the middle aqueous micellar phase, by means of a syringe and a hypodermic needle. The $4 \mathrm{~mL}$ aliquot was then filtered through a $0.2 \mu \mathrm{m}$ Nylon membrane filter (Acrodisc ${ }^{\circledR} 13 \mathrm{~mm}$ Syringe Filters, PALL Life Sciences, Ann Harbor, MI) into a $15 \mathrm{~mL}$ falcon tube. Carotenoid bioaccessibility was calculated as the percentage of carotenoids recovered in the final micellar phase compared to the original matrix's carotenoid content.

\subsection{Extractions}

Carotenoid extraction procedures have been described previously (Corte-Real, Bertucci et al., 2017). In short, aliquots of $4 \mathrm{~g}$ of spinach were wetted with $5 \mathrm{~mL}$ of $\mathrm{MeOH}$, and $1 \mathrm{~mL}$ of $30 \%$ aqueous $\mathrm{KOH}$ for saponification of chlorophylls, vortexed, sonicated, and incubated in the dark for $20 \mathrm{~min}$. Following centrifugation, supernatants were collected and spinach was re-extracted once with $9 \mathrm{~mL}$ hexane:acetone $(1: 1)$, and re-extracted with $9 \mathrm{~mL}$ hexane plus $4 \mathrm{~mL}$ of saturated $\mathrm{NaCl}$ and again with $4 \mathrm{~mL}$ of diethyl ether. Aliquots of the combined organic phases were dried under a stream of nitrogen using a TurboVapLV (Biotage, Eke, Belgium) apparatus (45 min at $25^{\circ} \mathrm{C}$ ). Dried extracts were re-dissolved in 5 to $7 \mathrm{~mL}$ of MTBE:MeOH (3:7), filtered through a $0.2 \mu \mathrm{m}$ polyvinylidene fluoride (PVDF) syringe filter (PALL Life Sciences, Ann Arbor, MI, USA), and the filter was rinsed in $100 \mu \mathrm{L}$ of MTBE:MeOH (3:7).

For digesta, $4 \mathrm{~mL}$ aliquots of the bioaccessible fraction, obtained after centrifugation, were extracted with $6 \mathrm{~mL}$ of hexane:acetone (2:1) with an additional $1 \mathrm{~mL}$ of aqueous $\mathrm{KOH}(30 \%)$ for saponification, vortexed and centrifuged $\left(2 \mathrm{~min}, 4000 \mathrm{~g}, 4^{\circ} \mathrm{C}\right)$. The supernatant 
was transferred to a new tube and the bioaccessible fraction re-extracted once with $5 \mathrm{~mL}$ of hexane and a second time with $5 \mathrm{~mL}$ of diethyl ether. The combined organic phases were evaporated under a stream of nitrogen in a TurboVap $\left(45 \mathrm{~min}, 25^{\circ} \mathrm{C}\right)$. The dried carotenoid extracts were spiked with an appropriate amount of internal standard (trans- $\beta$-apo- 8 '-carotenal at $10 \mu \mathrm{g} / \mathrm{mL}$ ), to obtain a final concentration of $1 \mu \mathrm{g} / \mathrm{mL}$ per sample, and were re-dissolved in $500 \mu \mathrm{L}$ of MTBE:MeOH (3:7). Samples were filtered through a $0.2 \mu \mathrm{m}$ PVDF syringe filter, into HPLC amber vials. The filter was then rinsed with $100 \mu \mathrm{L}$ of MTBE:MeOH, to reduce possible losses of carotenoids to the filter membrane, which was combined with the previous filtered sample, to a total volume of $600 \mu \mathrm{L}$.

\subsection{HPLC analysis}

Carotenoids were separated on an Agilent 1260 Infinity U-HPLC instrument (Agilent Technologies, De Kleetlaan Belgium S.A./N.V.). A gradient elution with (A) water: $\mathrm{MeOH}(60: 40)$ with $30 \mathrm{mM}$ of ammonium acetate, and (B) ACN:DCM (85:15), passing through an Accucore $^{\mathrm{TM}} \mathrm{C} 30$ column $(2.6 \mu \mathrm{m}$ particle size, $100 \mathrm{~mm}$ length, $3 \mathrm{~mm}$ diameter, from Thermo Fisher Scientific Inc.) was applied at $28{ }^{\circ} \mathrm{C}$, with $10 \mu \mathrm{L}$ injection volumes. Elution gradient was: $0 \mathrm{~min}, 48 \% \mathrm{~B}$; $4 \mathrm{~min}, 48 \% \mathrm{~B} ; 5 \mathrm{~min}, 52 \% \mathrm{~B} ; 11 \mathrm{~min}, 52 \% \mathrm{~B} ; 13 \mathrm{~min}, 75 \% \mathrm{~B} ; 18 \mathrm{~min}$, $90 \% \mathrm{~B} ; 35 \mathrm{~min}, 90 \% \mathrm{~B} ; 36 \mathrm{~min}, 42 \% \mathrm{~B}$. Carotenoids were detected by a coupled UV/VIS photodiode array detector, and identified according to their retention times and spectral data, compared to the corresponding external standards. All peaks were integrated manually at $440 \mathrm{~nm}$ (neoxanthin and violaxanthin), $450 \mathrm{~nm}$ (lutein and $\alpha$-carotene), $455 \mathrm{~nm}$ ( $\beta$-carotene and $\beta$-apo- 8 '-carotenal internal standard (IS)), according to each carotenoid absorption maximum. Quantification was achieved using the internal standard method.

\subsection{Micelle size and zeta potential analysis}

Aliquots of the aqueous micellar fraction were taken for analysis of the micelle size and zeta potential (indicator of the stability of the particles in solution). Aliquots were filtered prior to measurements, through a $0.2 \mu \mathrm{m}$ syringe filter (mixed cellulose esters; Millipore, Molsheim, France). The intensity-weighted mean hydrodynamic radius and zeta potential were determined by dynamic light scattering, and laser Doppler micro-electrophoresis, respectively. Measurements were done at $25^{\circ} \mathrm{C}$ with a Zetasizer Nano Zs instrument (Malvern Instruments, Malvern, UK).

\subsection{Fatty acid titration}

An acid-base titration was carried out to estimate the amount of free fatty acids in the digesta at the end of simulated gastro-intestinal digestions. Free fatty acids were titrated with sodium hydroxide $(\mathrm{NaOH} 0.01 \mathrm{M})$, using phenolphthalein as an indicator. In short, 5 drops of phenolphthalein $(0.1 \%$ in ethanol) were added to $5 \mathrm{~mL}$ of previously centrifuged sample. Sodium hydroxide $(\mathrm{NaOH} 0.01 \mathrm{M})$ was then added quantitatively and slowly via a burette, ensuring adequate stirring of the sample, until a colour change to pink was observed that remained stable for at least $30 \mathrm{~s}$.

\subsection{Statistical analysis}

Unless described otherwise, all values are expressed as mean \pm SD. Normality of distribution and equality of variance of the data were tested by normality plots and box plots, respectively. When required, log-transformation was conducted. All carotenoid bioaccessibility data was normalized to a respective control which was run for every set of analyses, in order to minimize day-to-day variations. A general linear model was developed with the effect of mineral concentration, lipid source, bile extract concentration and pancreatin concentration as fixed factors and bioaccessibility of individual carotenoids (lutein, $\beta$-carotene, $\alpha$-carotene, neoxanthin) as the observed dependent factor. A p-value below 0.05 (2-sided) was considered statistically significant. Following significant Fisher F-values, Bonferroni's post hoc-tests and Fisher-protected LSD tests (when comparing $<4$ groups) were conducted. The relation between the different tested outcomes (carotenoid bioaccessibility, particle size, particle zeta potential, moles of added $\mathrm{NaOH}$ ) was evaluated by Pearson correlation analyses.

\section{Results}

\subsection{General factors influencing carotenoid bioaccessibility from} spinach

In the present experimental design (Fig. 1), we tested for the effects of: 1) different magnesium concentrations; 2) different combinations of bile $(1 \mathrm{mM}$ or $8 \mathrm{mM})$ and pancreatin $(100 \mathrm{mg} / \mathrm{L}$ or 990 $\mathrm{mg} / \mathrm{L}$ ) concentrations; and 3) the effect of two different dietary lipid sources (canola oil and coffee creamer 10\% fat), on the bioaccessibility of carotenoids from a spinach-based test meal. As the model was fully factorial, all interactions were also studied.

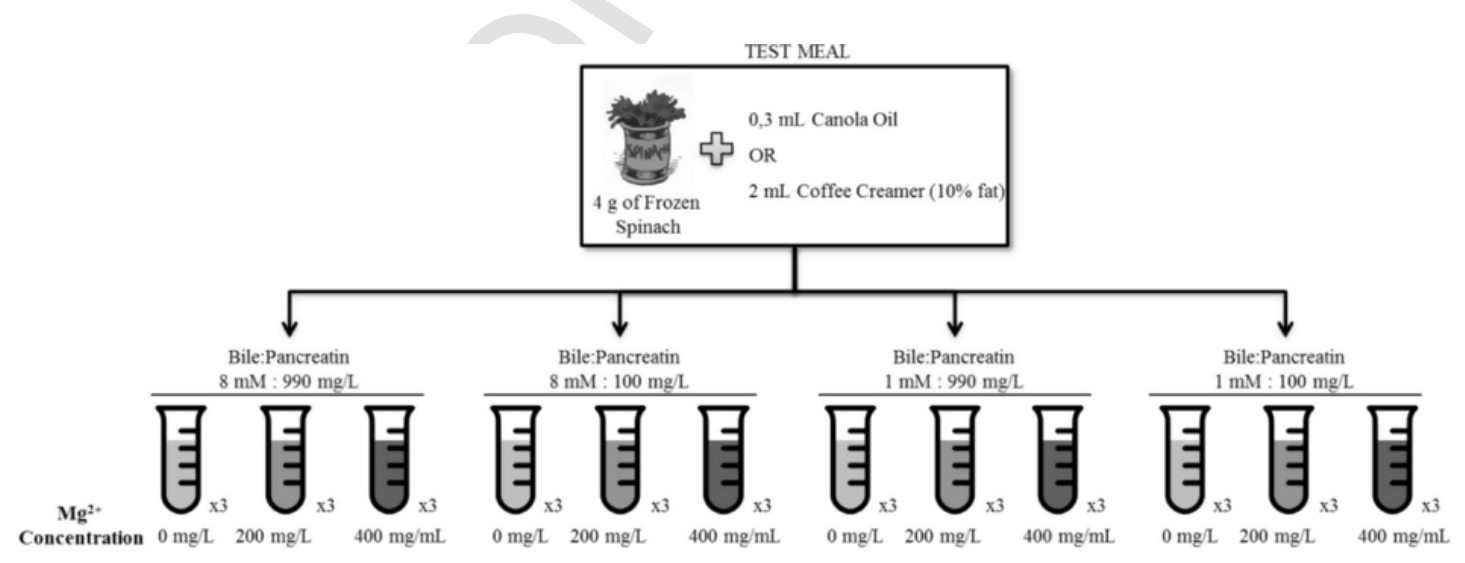

Fig. 1. Schematic diagram of the study design. 
All aforementioned factors significantly $(p<0.001)$ affected the bioaccessibility of spinach-borne total carotenoids (Supplemental Table 1) in this fully factorial model.

In the original spinach matrix, we identified and quantified violaxanthin, neoxanthin, lutein, $\beta$-carotene and $\alpha$-carotene (Table 1). However, violaxanthin could not be detected after digestion. Data for neoxanthin and $\alpha$-carotene bioaccessibility, due to their very low concentration, is not shown, even though they were considered for total carotenoid calculations. Bioaccessibility of carotenoids, following gastro-intestinal digestion, was generally low. When no magnesium was added, bioaccessibility of total carotenoids ranged between 0.05 and $4.83 \%$ (Fig. 2), depending on the combination of bile and pancreatin concentration.

In addition to bioaccessibility, the aqueous micellar fraction was also investigated for particle size and zeta potential, as well as the release of free fatty acids. Pearson correlation analyses showed that bioaccessibility was positively correlated with particle size (Pearson's $r=0.54, p<0.0001$ ) and free fatty acids released (Pearson's $r=0.65$, $\mathrm{p}<0.0001$ ), and negatively correlated with absolute zeta potential (Pearson's $\mathrm{r}=-0.60, \mathrm{p}<0.0001$ ).

\subsection{Influence of the concentration of bile and pancreatin on the effect of magnesium on carotenoid bioaccessibility}

The extent of the effect of magnesium on the bioaccessibility of total carotenoids was influenced by the concentration of bile $(\mathrm{p}<0.0001$ for magnesium $\times$ bile interaction), but not by pancreatin $(\mathrm{p}=0.4645$ for magnesium $\times$ pancreatin interaction, Supplemental Table 1). Samples digested with $1 \mathrm{mM}$ of bile were more susceptible to increasing concentrations of magnesium than samples digested with $8 \mathrm{mM}$, and magnesium concentrations of $200 \mathrm{mg} / \mathrm{L}$ and higher significantly $(\mathrm{p}<0.001)$ reduced the bioaccessibility of carotenoids (Fig. 2), by up to $100 \%$.

In the absence of magnesium, the presence of bile extract at $1 \mathrm{mM}$ resulted in a significantly lower percentage of total carotenoids recovered from the micellar phase when compared to $8 \mathrm{mM}(0.11 \pm 0.07 \%$ vs. $3.42 \pm 1.22 \%$, respectively). A similar effect was observed for lutein and $\beta$-carotene (Fig. 2). The effect of the concentration of pancreatin was less pronounced, and significant differences between samples digested with either $100 \mathrm{mg} / \mathrm{L}$ or $990 \mathrm{mg} / \mathrm{L}$ of pancreatin were only observed when bile acid concentration was $8 \mathrm{mM}(\mathrm{p}<0.001)$. Nevertheless, the negative effect of magnesium on carotenoid bioaccessibility was observed at all bile:pancreatin ratios.

\subsection{Influence of lipid source on the bioaccessibility of carotenoids}

Bioaccessibility differed significantly between samples digested with canola oil and those digested with coffee creamer, with a general tendency for a higher bioaccessibility of carotenoids from samples digested with coffee creamer (Table 3).

Table 1

Carotenoid content ( $\mu \mathrm{g} / \mathrm{g}$ wet weight) in the (raw and frozen) spinach matrix.

\begin{tabular}{lllllll}
\hline Matrix & Vio & Neo & Lut & $\alpha$-Car & $\beta$-Car & Total $^{*}$ \\
\hline $\begin{array}{l}\text { Spinach } \\
\begin{array}{l}\text { Spinacea } \\
\text { oleracea })\end{array}\end{array}$ & $30.5 \pm 10.8$ & $4.8 \pm 1.4$ & $74.3 \pm 13.2$ & $0.9 \pm 0.5$ & $7.1 \pm 1.0$ & $117 \pm 2<$ \\
\hline
\end{tabular}

Values represent mean \pm SD from $\mathrm{n}=4$. Vio: violaxanthin; Neo: neoxanthin; Lut: lutein; $\alpha$-Car: $\alpha$-carotene; $\beta$-Car: $\beta$-carotene.

* Represents the sum of all measured carotenoids.

\subsection{Factors influencing the size and zeta potential of the particles present in the micelle containing aqueous fraction}

All factors investigated had a significant $(\mathrm{p}<0.001)$ effect on the particle size of the aqueous micellar fraction (Fig. 3). Test meals digested with $8 \mathrm{mM}$ of bile tended to produce larger micelles although only samples digested with a bile and pancreatin concentration combination of $8 \mathrm{mM}$ and $990 \mathrm{mg} / \mathrm{L}$, respectively, produced particles which were significantly $(p<0.001)$ larger than for other conditions. For all the other bile:pancreatin combinations, the particle sizes did not differ significantly. Samples digested with coffee creamer produced significantly $(\mathrm{p}<0.001)$ bigger particles $(60.9 \pm 5.0 \mathrm{~nm}$, mean \pm SEM $)$ than those digested with canola oil $(25.8 \pm 4.9 \mathrm{~nm}$, mean \pm SEM $)$.

Also, the concentration of magnesium affected the size of the particles found in the micellar fraction. The presence of magnesium at $400 \mathrm{mg} / \mathrm{L}$ resulted in significantly smaller particles at the end of the digestion $(p<0.001)$. Varying concentrations of magnesium, bile and pancreatin, but not lipid source, also significantly $(\mathrm{p}<0.001)$ affected the zeta potential of the particles in solution. At a bile concentration of $1 \mathrm{mM}$ and pancreatin concentration of $100 \mathrm{mg} / \mathrm{L}$ (Figure B, lower panel), the average zeta potential of the digesta was $-4.9 \mathrm{mV}$, while at $8 \mathrm{mM}$ of bile extract and $990 \mathrm{mg} / \mathrm{L}$ of pancreatin the average zeta potential was $-27.4 \mathrm{mV}$ (Figure A, lower panel). As the concentration of magnesium increased, the absolute value of the zeta potential decreased, indicative of a more unstable system prone to particle aggregation due to reduced repulsive forces. Zeta potential also negatively correlated with particle size (Pearson's $r=-0.75, \mathrm{p}<0.0001$ ).

\subsection{Factors affecting the amount of free fatty acid released during digestion}

Based on the amount of $\mathrm{NaOH}$ dispensed for the titration of the gastro-intestinal digesta, statistical analysis revealed that the concentration of bile, pancreatin, and lipid source, significantly influenced the amount of free fatty acids in solution $(\mathrm{p}<0.001)$.

While the concentration of magnesium did not have any significant effect regarding fatty acid release on its own, a significant $(p<0.01)$ interaction with the other tested factors (concentration of bile, pancreatin, and lipid source) was observed. Samples digested with coffee creamer required on average more $\mathrm{NaOH}(40 \pm 1 \mathrm{nmol}$, mean $\pm \mathrm{SEM})$ than those digested with canola oil ( $32 \pm 1 \mathrm{nmol})$ (Table 2). Regarding the effects of bile and pancreatin concentrations in samples digested with $8 \mathrm{mM}$ of bile, the average amount of $\mathrm{NaOH}(44 \pm 1 \mathrm{nmol})$ was significantly $(\mathrm{p}<0.001)$ higher than for samples digested with $1 \mathrm{mM}$ of bile extract ( $29 \pm 1 \mathrm{nmol}$ ), suggesting incomplete digestion of the latter. The effect of pancreatin concentration, though being significant $(p<0.001)$, appeared less influential on lipolysis than the concentration of bile, with a slightly higher average amount of $\mathrm{NaOH}$ being required for samples digested with $990 \mathrm{mg} / \mathrm{L}$ of pancreatin $(40 \pm 1 \mathrm{nmol})$ than with $100 \mathrm{mg} / \mathrm{L}(33 \pm 1 \mathrm{nmol})$.

\section{Discussion}

Previously, we reported that varying concentrations of divalent minerals, including magnesium, can significantly affect the in vitro bioaccessibility of carotenoids, either of pure standards or from food sources (Biehler, Hoffmann et al., 2011; Corte-Real, Bertucci et al., 2017; Corte-Real et al., 2016), with the limitation that static in vitro models were used, with only 1 fixed concentration for bile extract and pancreatin, and thus digestive enzymes. For this reason, we here 
Bile : Pancreatin $(8 \mathrm{mM}: 990 \mathrm{mg} / \mathrm{L})$
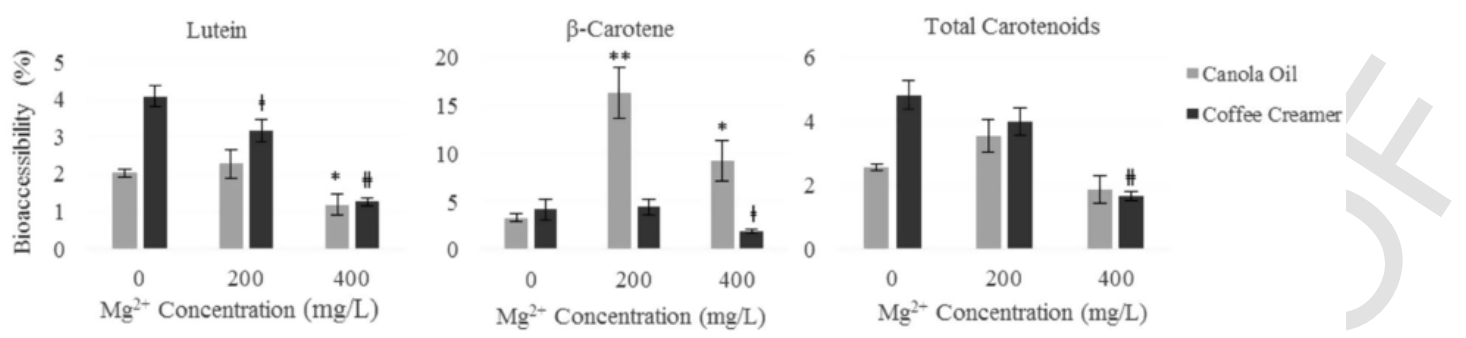

Bile : Pancreatin (1 mM : $990 \mathrm{mg} / \mathrm{L})$
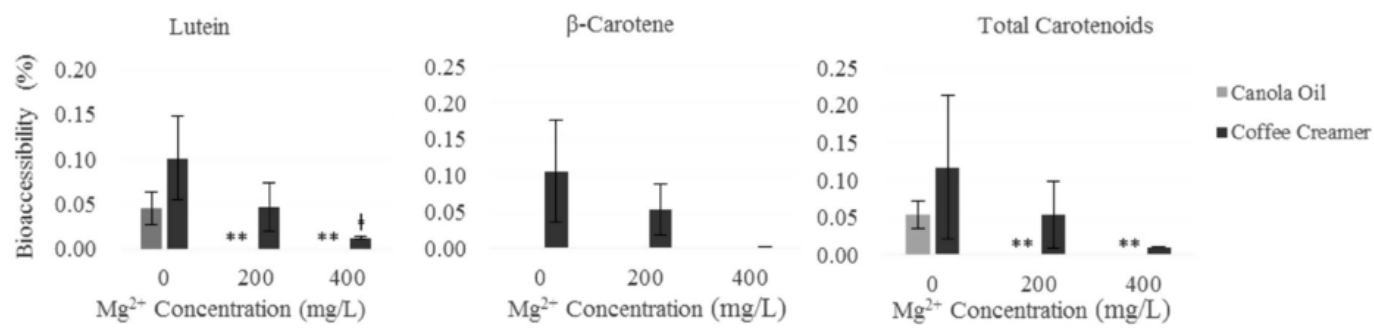

Bile : Pancreatin $(1 \mathrm{mM}: 100 \mathrm{mg} / \mathrm{L})$
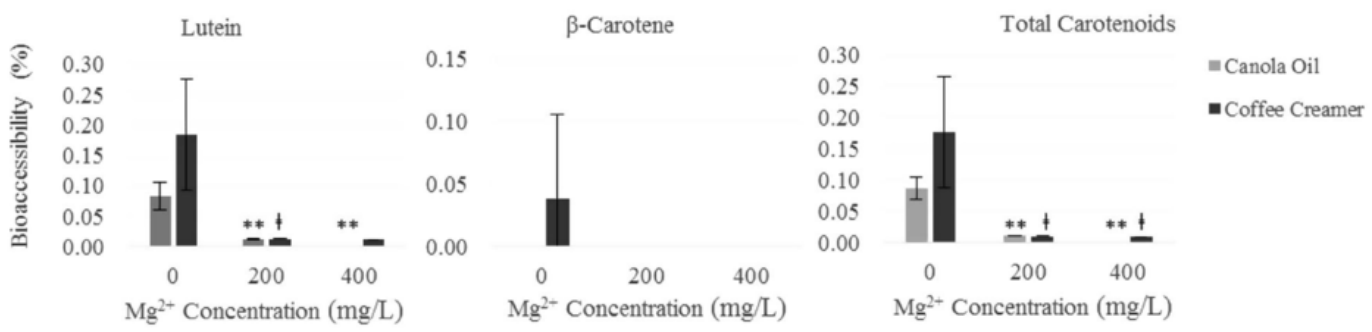

Bile : Pancreatin $(8 \mathrm{mM}: 100 \mathrm{mg} / \mathrm{L})$
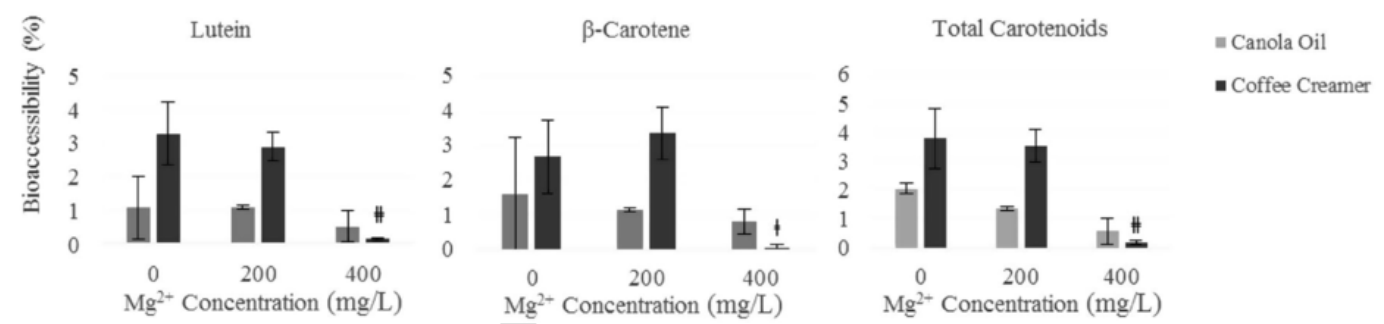

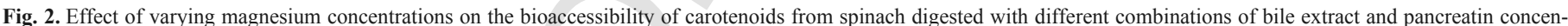

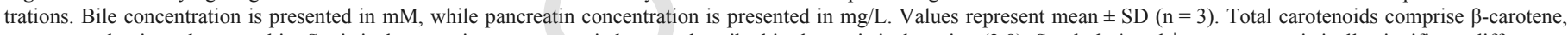

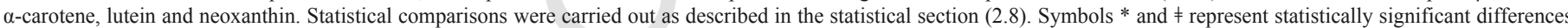

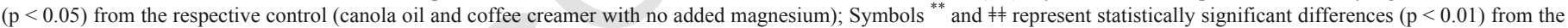
respective control (canola oil and coffee creamer with no added magnesium).

investigated whether altering the concentration of digestive enzymes and bile, with presumably crucial influence on carotenoid micelle formation (Bohn, 2012; Borel, 2003), would still yield similar negative influences of magnesium as a prominent dietary divalent mineral on carotenoid bioaccessibility, also in sight of recent contradictory results from human trials investigating the effect of calcium on carotenoid bioavailability (Borel et al., 2016; Corte-Real, Guignard et al., 2017). As less information was also available on magnesium compared to calcium regarding its interaction with bile salts and its role on lipid digestion, we focused on the second most abundant dietary cation. Finally, as the interaction of magnesium and carotenoids could depend on the type of lipid, two different lipid sources (canola oil and coffee creamer) were employed.

Similar as for earlier in vitro studies with calcium (Biehler, Hoffmann et al., 2011; Corte-Real, Bertucci et al., 2017; Corte-Real et al., 2016), it was found that increasing the concentration of magnesium significantly decreased the bioaccessibility of all individual and total carotenoids, especially at the highest concentration of $400 \mathrm{mg} /$ $\mathrm{L}$, chosen to reflect a supplement containing approximately the RDA (400 mg/d for adult men). The observed effects were in line with a decreased absolute zeta potential of the micellar fraction, suggestive of rather less stable particles. The results indicate that magnesium reduced carotenoid bioaccessibility by interfering with the ability of the 

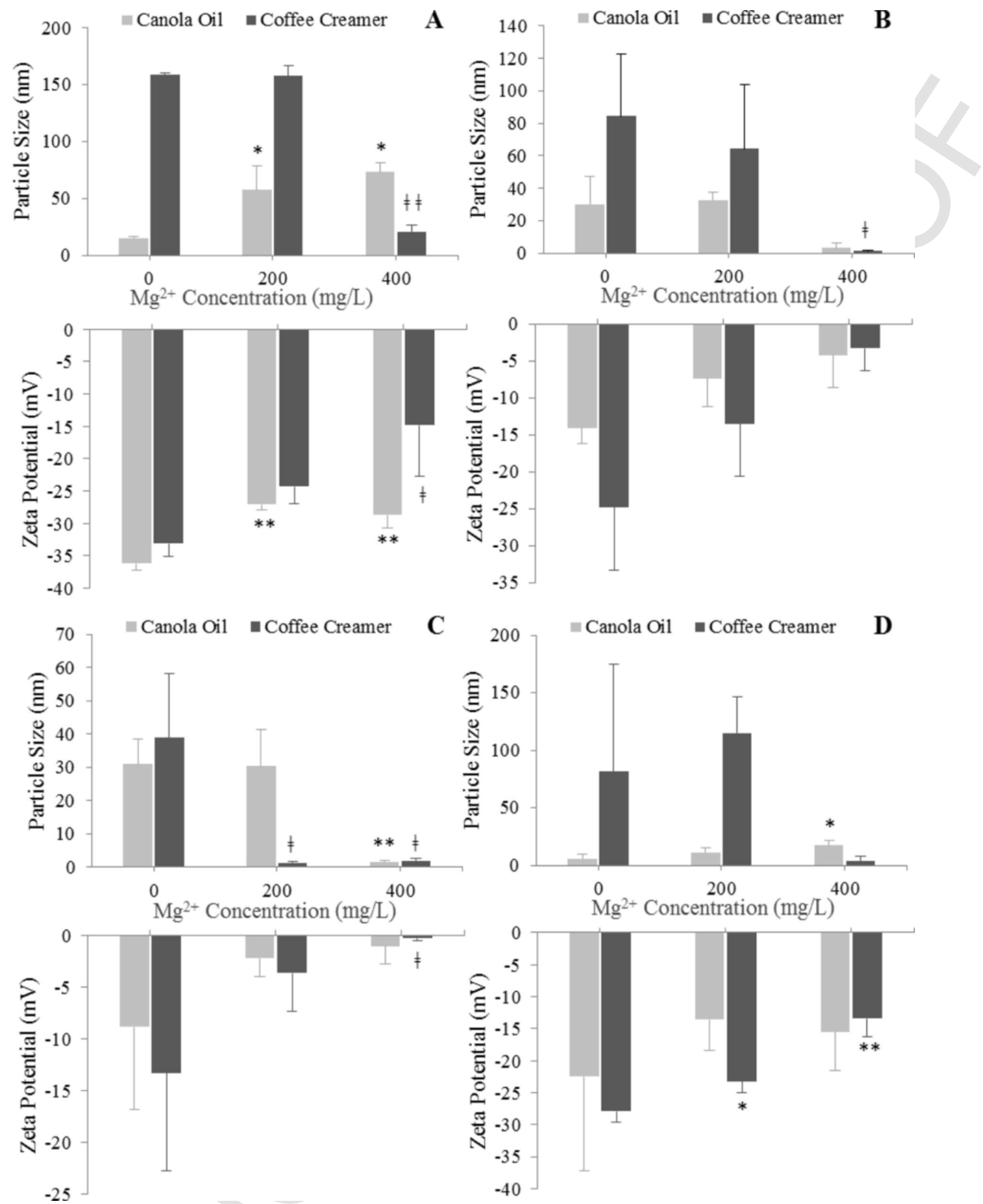

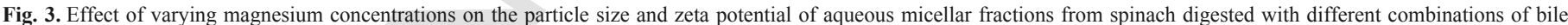

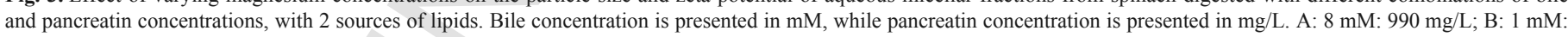

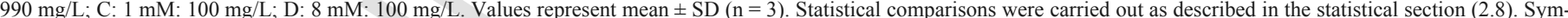

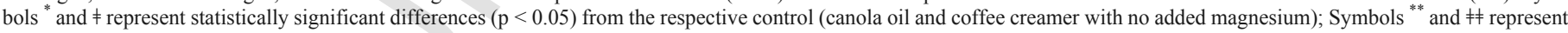
statistically significant differences $(\mathrm{p}<0.01)$ from the respective control (canola oil and coffee creamer with no added magnesium).

system to form stable mixed-micelles. Nevertheless, the action of magnesium on carotenoid bioaccessibility was largely influenced by the concentration of bile. In the presence of $1 \mathrm{mM}$ of bile, $200 \mathrm{mg} / \mathrm{L}$ of magnesium was sufficient to significantly reduce the micellarization of total carotenoids from spinach, while at $8 \mathrm{mM}$ of bile the same effect was only observed at $400 \mathrm{mg} / \mathrm{L}$ of magnesium. Contrarily, concentrations of pancreatin affected bioaccessibility of carotenoids to a lesser extent, and no significant differences were observed for total carotenoids between lowest (100 mg/L) and highest $(990 \mathrm{mg} / \mathrm{L})$ concentration when sufficient bile was present. This indicates that the 
Table 2

Amount (nmol) of $0.01 \mathrm{M} \mathrm{NaOH}$ required for the neutralization of liberated free fatty acids in the digesta following gastro-intestinal digestion. Phenolphthalein was used as a $\mathrm{pH}$ indicator. Samples were titrated until a color change to pink, remaining for at least $30 \mathrm{~s}$, was observed.

\begin{tabular}{llll}
\hline Canola oil & \multicolumn{3}{l}{ Magnesium concentration } \\
\hline & $0 \mathrm{mg} / \mathrm{L}$ & $200 \mathrm{mg} / \mathrm{L}$ & $400 \mathrm{mg} / \mathrm{L}$ \\
\hline concentration bile: pancreatin & & & \\
$1 \mathrm{mM}: 100 \mathrm{mg} / \mathrm{L}$ & $19 \pm 2^{\mathrm{C}}$ & $21 \pm 1^{\mathrm{D}}$ & $22 \pm 3^{\mathrm{C}}$ \\
$8 \mathrm{mM}: 100 \mathrm{mg} / \mathrm{L}$ & $37 \pm 1^{\mathrm{A}}$ & $36 \pm 1^{\mathrm{C}}$ & $39 \pm 6^{\mathrm{A}}$ \\
$1 \mathrm{mM}: 990 \mathrm{mg} / \mathrm{L}$ & $28 \pm 3^{\mathrm{B}}$ & $27 \pm 1^{\mathrm{B}}$ & $25 \pm 1^{\mathrm{A}, \mathrm{C}}$ \\
$8 \mathrm{mM}: 990 \mathrm{mg} / \mathrm{L}$ & $37 \pm 1^{\mathrm{A} ; \mathrm{a}}$ & $55 \pm 1^{\mathrm{A} ; \mathrm{b}}$ & $49 \pm 2^{\mathrm{A} ; \mathrm{c}}$ \\
Coffee creamer & & \\
concentration bile: pancreatin $_{1 \mathrm{mM}: 100 \mathrm{mg} / \mathrm{L}}$ & & \\
$8 \mathrm{mM}: 100 \mathrm{mg} / \mathrm{L}$ & $24 \pm 3^{\mathrm{B} ; \mathrm{a}}$ & $30 \pm 3^{\mathrm{B} ; \mathrm{a}, \mathrm{b}}$ & $32 \pm 1^{\mathrm{B} ; \mathrm{b}}$ \\
$1 \mathrm{mM}: 990 \mathrm{mg} / \mathrm{L}$ & $52 \pm 5^{\mathrm{A} ; \mathrm{a}}$ & $50 \pm 1^{\mathrm{C} ; \mathrm{a}, \mathrm{b}}$ & $38 \pm 2^{\mathrm{A}, \mathrm{B} ; \mathrm{c}}$ \\
$8 \mathrm{mM}: 990 \mathrm{mg} / \mathrm{L}$ & $42^{\mathrm{A}} \pm 6^{\mathrm{A}}$ & $40 \pm 6^{\mathrm{A}, \mathrm{B}}$ & $39 \pm 3^{\mathrm{A}}$ \\
\hline
\end{tabular}

Values represent mean $\pm \mathrm{SD}$ of triplicates.

Values not sharing an upper-case superscript within one column are significantly different $(\mathrm{P}<0.05)$. Values not sharing a lower-case superscript within the same row are significantly different $(\mathrm{P}<0.05)$, unless no superscripts are indicated.

Table 3

Effect of the lipid source on the bioaccessibility (\%) of spinach individual and total carotenoids, digested with either $1 \mathrm{mM}$ or $8 \mathrm{mM}$ of bile, without the influence of added magnesium.

\begin{tabular}{llll}
\hline & Lutein (\%) & $\beta$-Carotene $(\%)$ & Total Carotenoids (\%) $^{*}$ \\
\hline Canola Oil & & & \\
Bile: $1 \mathrm{mM}$ & $0.06 \pm 0.30$ & $0.00 \pm 0.00$ & $0.07 \pm 0.02$ \\
Bile: $8 \mathrm{mM}$ & $1.86 \pm 0.25$ & $1.32 \pm 1.62$ & $1.10 \pm 1.21$ \\
Coffee Creamer $(10 \%$ fat $)$ & & \\
Bile: $1 \mathrm{mM}$ & $0.143 \pm 0.08$ & $0.07 \pm 0.08$ & $0.15 \pm 0.08$ \\
Bile: $8 \mathrm{mM}$ & $3.68 \pm 0.76$ & $3.40 \pm 1.23$ & $4.31 \pm 0.91$
\end{tabular}

Values represent mean \pm SD of triplicates.

All pairwise comparisons between $1 \mathrm{mM}$ and $8 \mathrm{mM}$ of bile were found to be statistically significant $(\mathrm{p}<0.05)$

* Total carotenoids represents the sum of the sum of lutein, $\beta$-carotene, $\alpha$-carotene and neoxanthin. Each carotenoid concentration was determined individually first by means of external standard calibration curves, and concentrations were then added to yield total carotenoid concentration.

negative effects persisted for a range of physiologically plausible concentrations of bile salts and pancreatin, and thus digestive enzymes such as lipase.

Previous studies have emphasized that in vitro bioaccessibility of carotenoids is dependent on bile (Tyssandier, Lyan, \& Borel, 2001) and pancreatic enzyme concentration (Biehler, Hoffmann, Krause, and Bohn, 2011). The capacity of the system to form mixed micelles is related to the bile salt critical micelle concentration (CMC). Below the $\mathrm{CMC}$, transfer of carotenoids from the matrix into the lipid oil phase is inhibited (Rich, Faulks, Wickham, \& Fillery-Travis, 2003). Most bile salts have a CMC above $2 \mathrm{mM}$, so a bile concentration of 1 $\mathrm{mM}$ may have been insufficient to initiate micellar formation. Also, a lower concentration of bile would have been more susceptible to the effects of magnesium, removing the majority of available bile salts via precipitation.

The inhibitory effect of a low concentration of bile and, to a lesser extent, of pancreatin on carotenoid bioaccessibility, was also observed by the extent of lipolysis, as indicated by the amount of $\mathrm{NaOH}$ needed for fatty acid neutralization (Table 2). Neutralization of fatty acids required significantly less $\mathrm{NaOH}$ in samples digested with $1 \mathrm{mM}$ than with $8 \mathrm{mM}$, and in samples digested with $100 \mathrm{mg} / \mathrm{L}$ of pancreatin versus $990 \mathrm{mg} / \mathrm{L}$. In fact, after digestion with $1 \mathrm{mM}$ of bile extract and coffee creamer, we observed a thick layer of undigested fatty material floating in the test tubes. This layer was not present in samples digested with $8 \mathrm{mM}$ of bile.

The presence of dietary fat can significantly improve carotenoid bioaccessibility, but may depend on the amount and type of lipid added (Gleize et al., 2013; Goltz, Campbell, Chitchumroonchokchai, Failla, \& Ferruzzi, 2012). Here, we tested for differences in carotenoid bioaccessibility digested with or without magnesium when using either a vegetable or an animal source of fat, containing approximately the same amount of lipids. Significant differences between the two types of fat were encountered, with a somewhat higher bioaccessibility with coffee creamer. Also, there was a significant interaction of magnesium and lipid type, indicating that the effect of magnesium depended on the type of lipid added. In milk, the lipid phase exists in the form of an oil-in-water emulsion composed of triglycerides, fatty acids, phospholipids and proteins, also termed as a milk fat globule membrane (MFGM) (Contarini \& Povolo, 2013). The properties of the MFGM as an emulsifier may give an advantage to dairy products for the transfer of lipid-soluble microconstituents including carotenoids into bile salts and mixed micelles (Bezelgues, Morgan, Palomo, Crosset-Perrotin, \& Ducret, 2009).

As a crucial stabilizing element of mixed micelles, bile salts decrease the surface tension of the water-lipid interface, stabilizing emulsions (Hofmann \& Mysels, 1987), giving them a negative charge. In our experiments, the zeta potential of the micellar fractions depended on the bile concentration. Micellar fractions had smaller absolute zeta potentials when samples were digested with $1 \mathrm{mM}$ compared to those digested with $8 \mathrm{mM}$ of bile, similar to an earlier study (Wickham, Garrood, Leney, Wilson, \& Fillery-Travis, 1998). Increasing concentrations of magnesium also decreased the absolute zeta potential, for both lipid sources. In a study by Wickham et al. (1998), the authors showed that at bile concentrations of $6 \mathrm{mM}$, increasing calcium concentration reduced the absolute zeta potential of the emulsions, suggesting that this might be due to the role of calcium to shield the surface charge of the emulsion droplets.

Spontaneous formation of mixed micelles will only occur when bile concentrations exceed those of the CMC. Divalent cations binding to bile salts can alter their solubility, and the solubility product of the cation salt can be lower than the CMC of bile acids, resulting in the precipitation of cation bile salts (Hofmann \& Mysels, 1992). It was shown that calcium binding led to a concentration-dependent formation of insoluble bile salts (Baruch, Lichtenberg, Barak, \& Nir, 1991; Hofmann \& Mysels, 1992). We assume a similar behavior in the present study for magnesium, with the magnesium salts of bile acids reaching their solubility product at concentrations inferior to the $\mathrm{CMC}$, leading to precipitation.

However, binding to bile salts might not entirely explain the effect of magnesium on carotenoid bioaccessibility, as magnesium also binds free fatty acids to form soaps of low solubility. In early studies with rodent models, authors found that both calcium and magnesium lowered the digestibility of poorly absorbable fats with a marked increase in the excretion of fat in form of soaps (Cheng, Morehouse, \& Deuel, 1949; Tadayyon \& Lutwak, 1969). Thus, the observed decrease in bioaccessibility at high concentrations of magnesium might have been the result of its binding to both fatty acids and bile acids, resulting in the formation of soaps and precipitated bile salts.

\section{Conclusions}

In summary, magnesium, at high physiological concentrations, negatively affected the bioaccessibility of carotenoids from a spinach matrix in vitro, at 2 different concentrations of bile $(1$ or $8 \mathrm{mM})$ and 
pancreatin (100 and $900 \mathrm{mg} / \mathrm{L})$. This suggests an inhibitory effect of magnesium on carotenoid bioaccessibility over a range of different digestive conditions, at least at highest concentrations of magnesium studied, possibly more reflective of an in vivo adaptive situation. The results obtained are thus partly in support of results obtained earlier including other minerals, employing a static in vitro digestion model at fixed concentrations of bile extract and pancreatin, as suggested in a recent consensus model (Minekus et al., 2014).

However, the effect of magnesium was especially accentuated in the presence of low bile concentrations $(1 \mathrm{mM})$ and, to a lesser extent, at low concentrations of pancreatin $(100 \mathrm{mg} / \mathrm{L})$, indicating that under such critical concentrations, the negative effect of magnesium, and perhaps, though not studied here, other divalent cations, is more pronounced. Although bile concentrations as low as $1 \mathrm{mM}$ are not normally found in vivo in healthy subjects, we could imagine this happening in e.g. cholestasis, where fat-soluble micronutrient malabsorption is known to be an issue (Silva et al., 2015). Further in vivo investigations are necessary to fully assess the extent to which magnesium could potentially affect carotenoid bioavailability.

\section{Conflict of interest}

The authors declare no conflict of interest.

\section{Acknowledgments}

The authors are grateful for the support of the Fonds National de la Recherche Luxembourg (Grant No. C11/SR/1268260). The help of Boris Untereiner with extractions and digestions is greatly appreciated. The insights obtained from the EU COST ACTION EUROCAROTEN (CA 15136) are much appreciated.

\section{Appendix A. Supplementary data}

Supplementary data associated with this article can be found, in the online version, at http://dx.doi.org/10.1016/j.foodchem.2017.06.147.

\section{References}

Alminger, M., Aura, A.M., Bohn, T., Dufour, C., El, S.N., Gomes, A., ... Santos, C.N 2014. In vitro models for studying secondary plant metabolite digestion and bioaccessibility. Comprehensive Reviews in Food Science and Food Safety $13,413-436$

Atteh, J.O., Leeson, S., 1985. Influence of age, dietary cholic acid, and calcium levels on performance, utilization of free fatty acids, and bone mineralization in broilers Poultry Science 64 (10), 1959-1971.

Baruch, E., Lichtenberg, D., Barak, P., Nir, S., 1991. Calcium binding to bile salts Chemistry and Physics of Lipids 57 (1), 17-27.

Bezelgues, J.B., Morgan, F., Palomo, G., Crosset-Perrotin, L., Ducret, P., 2009. Short communication: Milk fat globule membrane as a potential delivery system for liposoluble nutrients. Journal of Dairy Science 92 (6), 2524-2528.

Biehler, E., Bohn, T., 2010. Methods for assessing aspects of carotenoid bioavailability. Current Nutrition \& Food Science 6 (1), 44-69.

Biehler, E., Hoffmann, L., Krause, E., Bohn, T., 2011. Divalent minerals decrease micellarization and uptake of carotenoids and digestion products into Caco- 2 cells. Journal of Nutrition 141 (10), 1769-1776.

Biehler, E., Kaulmann, A., Hoffmann, L., Krause, E., Bohn, T., 2011. Dietary and host-related factors influencing carotenoid bioaccessibility from spinach (Spinacia oleracea). Food Chemistry 125 (4), 1328-1334.

Bohn, T., 2008. Dietary factors influencing magnesium absorption in humans. Current Nutrition and Food Science 4, 53-72

Bohn, T., 2012. Provitamin A carotenoids - Occurrence, intake, and bioavailability. In Preedy, V. (Ed.), Vitamin A and carotenoids: Chemistry, analysis, function and effects (food and nutritional components in focus)). RSC Publishing, London.

Bohn, T., Desmarchelier, C., Dragsted, L.O., Nielsen, C.S., Stahl, W., Ruhl, R., ... Borel, P., 2017. Host-related factors explaining interindividual variability of carotenoid bioavailability and tissue concentrations in humans. Molecular Nutrition \& Food Research http://dx.doi.org/10.1002/mnfr.201600685.

Borel, P., 2003. Factors affecting intestinal absorption of highly lipophilic food microconstituents (fat-soluble vitamins, carotenoids and phytosterols). Clinical Chemistry and Laboratory Medicine 41 (8), 979-994.

Borel, P., Desmarchelier, C., Dumont, U., Halimi, C., Lairon, D., Page, D., ... Remond, D., 2016. Dietary calcium impairs tomato lycopene bioavailability in healthy humans. British Journal of Nutrition 116 (12), 2091-2096.

Boyd, O.F., Crum, C.L., Lyman, D.O., 1932. The absorption of calcium soaps and the relation of dietary fat to calcium utilization in the white rat. The Journal of Biological Chemistry 95, 29-41.

Britton, G., Liaaen-Jensen, S., Pfander, H., 2009. Carotenoids, Vol. 5. Birkhäuser, Basel.

Castenmiller, J.J., West, C.E., Linssen, J.P., van het Hof, K.H., Voragen, A.G., 1999. The food matrix of spinach is a limiting factor in determining the bioavailability of beta-carotene and to a lesser extent of lutein in humans. Journal of Nutrition 129 (2), 349-355.

Cheng, A.L., Morehouse, M.G., Deuel Jr., H.J., 1949. The effect of the level of dietary calcium and magnesium on the digestibility of fatty acids, simple triglycerides and some natural and hydrogenated fats. Journal of Nutrition 37 (2), 237-250.

Contarini, G., Povolo, M., 2013. Phospholipids in milk fat: Composition, biological and technological significance, and analytical strategies. International Journal of Molecular Sciences 14 (2), 2808-2831.

Corte-Real, J., Bertucci, M., Soukoulis, C., Desmarchelier, C., Borel, P., Richling, E., ... Bohn, T., 2017. Negative effects of divalent mineral cations on the bioaccessibility of carotenoids from plant food matrices and related physical properties of gastro-intestinal fluids. Food and Function 8 (3), 1008-1019.

Corte-Real, J., Guignard, C., Gantenbein, M., Chioti, A., Burgard, K., Hoffmann, L., Richling, E., \& Bohn, T. (2017). No influence of supplemental dietary calcium intake on the bioavailability of spinach carotenoids in humans. British Journal of Nutrition, submitted.

Corte-Real, J., Iddir, M., Soukoulis, C., Richling, E., Hoffmann, L., \& Bohn, T. (2016). Effect of divalent minerals on the bioaccessibility of pure carotenoids and on physical properties of gastro-intestinal fluids. Food Chemistry, 197(Pt A), 546-553.

Corte-Real, J., Richling, E., Hoffmann, L., Bohn, T., 2014. Selective factors governing in vitro beta-carotene bioaccessibility: negative influence of low filtration cutoffs and alterations by emulsifiers and food matrices. Nutrition Research 34 (12), $1101-1110$.

Desmarchelier, C., \& Borel, P. (2017). Overview of carotenoid bioavailability determinants: From dietary factors to host genetic variations. Trends in Food Science \& Technology, in press.

Gleize, B., Tourniaire, F., Depezay, L., Bott, R., Nowicki, M., Albino, L., ... Borel, P., 2013. Effect of type of TAG fatty acids on lutein and zeaxanthin bioavailability. British Journal of Nutrition 110 (1), 1-10.

Goltz, S.R., Campbell, W.W., Chitchumroonchokchai, C., Failla, M.L., Ferruzzi, M.G., 2012. Meal triacylglycerol profile modulates postprandial absorption of carotenoids in humans. Molecular Nutrition and Food Research 56 (6), 866-877.

Gu, J.J., Hofmann, A.F., Ton-Nu, H.T., Schteingart, C.D., Mysels, K.J., 1992. Solubility of calcium salts of unconjugated and conjugated natural bile acids. Journal of Lipid Research 33 (5), 635-646.

Hofmann, A.F., Mysels, K.J., 1987. Bile salts as biological surfactants. Colloids and Surfaces 30 (1), 145-173.

Hofmann, A.F., Mysels, K.J., 1992. Bile acid solubility and precipitation in vitro and in vivo: The role of conjugation, $\mathrm{pH}$, and $\mathrm{Ca} 2+$ ions. Journal of Lipid Research $33(5), 617-626$.

Institute of Medicine, 2005. Dietary reference intakes for calcium, phosphorus, magnesium, vitamin D and fluoride. Natinal Academy Press, Washington, D.C.

Kaulmann, A., Bohn, T., 2014. Carotenoids, inflammation, and oxidative stress-implications of cellular signaling pathways and relation to chronic disease prevention. Nutrition Research 34 (11), 907-929.

Krinsky, N.I., Yeum, K.J., 2003. Carotenoid-radical interactions. Biochemical and Biophysical Research Communications 305 (3), 754-760.

Lima, V.C., Rosen, R.B., Farah, M., 2016. Macular pigment in retinal health and disease. International Journal of Retina and Vitreous 2, 19

Minekus, M., Alminger, M., Alvito, P., Ballance, S., Bohn, T., Bourlieu, C., ... Brodkorb, A., 2014. A standardised static in vitro digestion method suitable for food An international consensus. Food and Function 5 (6), 1113-1124.

Rich, G.T., Faulks, R.M., Wickham, M.S., Fillery-Travis, A., 2003. Solubilization of carotenoids from carrot juice and spinach in lipid phases: II. Modeling the duodenal environment. Lipids 38 (9), 947-956.

Rock, C.L., Lovalvo, J.L., Emenhiser, C., Ruffin, M.T., Flatt, S.W., Schwartz, S.J., 1998. Bioavailability of beta-carotene is lower in raw than in processed carrots and spinach in women. Journal of Nutrition 128 (5), 913-916.

Scripsema, N.K., Hu, D.N., Rosen, R.B., 2015. Lutein, zeaxanthin, and meso-zeaxanthin in the clinical management of eye disease. Journal of Ophtalmology 2015,865179 
Silva, M., Gomes, S., Peixoto, A., Torres-Ramalho, P., Cardoso, H., Azevedo, R., .. Macedo, G., 2015. Nutrition in chronic liver disease. GE Portuguese Journal of Gastroenterology 22 (6), 268-276.

Tadayyon, B., Lutwak, L., 1969. Interrelationship of triglycerides with calcium, magnesium and phosphorus in the rat. Journal of Nutrition 97 (2), 246-254.

Tyssandier, V., Lyan, B., Borel, P., 2001. Main factors governing the transfer of carotenoids from emulsion lipid droplets to micelles. Biochimica and Biophysica Acta 1533 (3), 285-292.
Wickham, M., Garrood, M., Leney, J., Wilson, P.D., Fillery-Travis, A., 1998. Modification of a phospholipid stabilized emulsion interface by bile salt: Effect on pancreatic lipase activity. Journal of Lipid Research 39 (3), 623-632. 